\title{
MAKINGtheLINK: A school-based intervention to improve help-seeking for substance use problems
}

Dan I. Lubman ${ }^{1,2}$ Ali Cheetham ${ }^{1,2}$ Bonita J. Berridge ${ }^{1,2} \&$ Lisa McKay-Brown ${ }^{3,4}$

1 Turning Point, Eastern Health, 54-62 Gertrude Street, Fitzroy 3065, Victoria, Australia

2 Eastern Health Clinical School, Monash University, Level 2, 5 Arnold Street, Box Hill 3128, Victoria, Australia

3 Travancore School, Victorian Department of Education and Training, 50 Flemington Street, Travancore, 3032, Victoria, Australia

4 Melbourne Graduate School of Education, University of Melbourne, Level 6, 100 Leicester St University of Melbourne, 3010, Victoria Australia

Corresponding author: Prof Dan I. Lubman, Turning Point, 54-62 Gertrude St, Fitzroy VIC 3065, Fax 6103 9416 3420, Ph 038413 8413, Email dan.lubman@monash.edu

\section{Acknowledgements}

We thank the young people who participated in the study, the participating high schools, and the Department of Health and Human Services and Department of Education and Early Childhood Development, Victoria, Australia for their support.

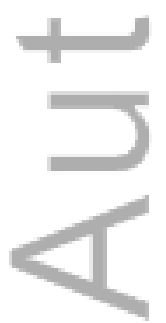

This is the author manuscript accepted for publication and has undergone full peer review but has not been through the copyediting, typesetting, pagination and proofreading process, which may lead to differences between this version and the Version of Record. Please cite this article as doi: 10.1111/eip.12402

This article is protected by copyright. All rights reserved. 


\section{Abstract}

Aim: Many young people are reluctant to seek professional help for alcohol and other substance use problems, preferring to rely on family and friends. MAKINGtheLINK is a school-based intervention that teaches adolescents how to help their peers overcome barriers to engaging with professional help. The current study examined the effect of the MAKINGtheLINK program in a sample of 12-15 year old students.

Methods: Participants included 338 Grade 8 students (49\% male, 51\% female) recruited from the three schools in Victoria, Australia. Participants completed questionnaires measuring barriers to professional help-seeking, help-seeking intentions, and confidence to seek help at three time points (pre-intervention, post-intervention, and 6-week follow-up). A non-controlled repeated measures design was used to assess the effect of the program on help-seeking across time points.

Results: The program decreased barriers, increased intentions to seek help from formal sources, decreased intentions to seek help from family, and increased confidence to seek help for a peer. The decrease in barriers was maintained at the 6-week follow-up, as were decreased intentions to seek help from family members, and increased intentions to seek help from school counsellors and alcohol and drug workers. The effects of the intervention did not differ substantially between males and females.

\section{Conclusions:}

MAKINGtheLINK is the first intervention to focus on overcoming barriers to help-seeking for substance use problems by helping adolescents develop skills to support their peers. The intervention has promise as a means of facilitating help-seeking during adolescence, although further research is needed to test its effectiveness in a more rigorous design.

Key words: Adolescence, alcohol, help-seeking, mental health, school

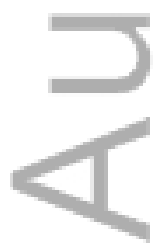




\section{INTRODUCTION}

Increasing early intervention efforts are key to reducing the harms associated with adolescent substance use $(1,2)$. However, many young people are reluctant to seek professional help for problems related to their alcohol or drug use $(3,4)$. Studies have identified barriers to seeking treatment that may explain these findings, including concerns about stigma or judgement, limited trust in health professionals, a lack of understanding of professional confidentiality obligations, poor emotional competence, as well as the young person's belief that they should be able to resolve their own problems (5-8). These barriers constitute a significant challenge for health promotion activities targeting adolescent substance use, and highlight the need for programs that facilitate help-seeking skills amongst young people.

When adolescents do seek help for substance use problems, they often turn to peers or family members for support $(3,9-12)$. As peers become increasingly influential during the teenage years (13), adolescents are ideally placed to act as 'gate-keepers' to mental health services by supporting other young people and encouraging them to access appropriate professional help (14). However, studies have found that many adolescents demonstrate poor mental health literacy, including a limited ability to recognise specific disorders, poor knowledge of how to seek mental health information, as well as attitudes that do not promote problem recognition or appropriate help-seeking (15). Further, while approximately $50 \%$ of Australian secondary school students drink at harmful levels by the age of 17 (16), many young people underestimate the risks associated with harmful drinking (17-19). Studies also suggest that there may be unique barriers to seeking help for substance use problems, such as beliefs regarding the positive effects of substance use or attachment to a drug-using identity [7]. Teaching adolescents how to overcome these barriers is likely to improve gate-keeping skills and increase early identification and treatment of substance use problems.

Research examining help-seeking patterns suggests that females are more likely to seek help for mental health problems than males, with some evidence to suggest such gender differences are more pronounced at earlier ages (20). Indeed, females report less stigma or pressure in relation to concealing their problems, demonstrate better mental health literacy, and are more open and expressive in talking about mental health issues (21-23). Accordingly, females report greater intentions to seek help from peers, family, and professional sources $(13,22,24-26)$, as well as online $(27,28)$. However, only a small number of studies have examined gender differences in help-seeking for substance use problems $(11,29,30)$, and it is unclear whether the impact of help-seeking interventions differs between males and females, particularly during adolescence. 
The MAKINGtheLINK: Seeking Help for Risky Drinking program is a school-based intervention designed to address identified barriers and enablers to adolescent help-seeking, in order to increase future help-seeking for substance-related problems before they reach a level of clinical significance. The current study examined the effect of the MAKINGtheLINK intervention on help-seeking barriers, intentions, and confidence in a sample of 12-15 year old students. It was hypothesised that the program would decrease barriers to seeking professional help, increase help-seeking intentions, and increase participants' confidence to seek help for themselves and for their peers. Gender was included in the analyses, in order to examine whether the effect of the program differed between males and females. Consistent with the mental health research literature, we expected that females would report fewer barriers to help-seeking, greater confidence, and greater intentions. However, we did not expect that the effect of the program would differ as a function of gender.

\section{METHODS}

\section{Design}

The MAKINGtheLINK: Seeking Help for Risky Drinking program is an adaptation of a previous school-based intervention that aimed to increase help-seeking for cannabis and mental health problems during adolescence (31). MAKINGtheLINK focuses on teaching adolescents the skills needed to identify mental health issues in their peers, and helping them overcome barriers to accessing and engaging with professional help (i.e., teaching practical steps for students to become effective gate-keepers). The program draws on two models of behaviour change - the Information-Motivation-Behavioural Skills Model (IMB) and Theory of Planned Behaviour (TpB). The IMB model is a well-validated, comprehensive health behaviour change framework that has been used in schools for HIV education and prevention (32). The model proposes that preventative behaviour is a function of the extent to which the individual is well-informed, motivated, and in possession of the skills needed to execute the behaviour. The $\mathrm{TpB}$ is a health behaviour change framework that has been used extensively in experimental health intervention trials (33), and proposes that behavioural outcomes are determined by intention and perceived behavioural control. In the MAKINGtheLINK intervention, the help-seeking activities included providing students with information about how to seek help and from whom (information), investigating perceived barriers to helpseeking (beliefs, intentions), and providing opportunities and videos for skill rehearsal (behavioural skills), which according to our composite model will lead to increased intentions to seek help as well as actual help-seeking behaviour (behavioural outcome). The program 
comprises an implementation guide, a teacher manual, six interactive discussion-based activities, including an animation about the effects of alcohol on the developing brain and two vodcasts modelling how to assist a friend to seek help. A non-controlled repeated measures design was used to assess the effect of the program on help-seeking at three time points (pre-intervention, post-intervention, and 6-week follow-up).

\section{Participants}

A convenience sample of three high schools in Victoria, Australia, was recruited. Two of the schools were in the outer suburbs (one large, one medium size), and one was in the inner-city (small).All students in Grade 8 (aged 12-15) from the three schools were eligible to participate in the study $(n=330)$. Student participation was entirely voluntary, and informed consent for all time points was obtained from the students' parents prior to participation. Ethics approval was obtained from ethics committees at Eastern Health and the Department of Edueation and Early Childhood Development, Victoria.

\section{Procedure}

The intervention was delivered over three hours on two separate occasions in each school (one two-hour session and another one-hour session in the same week) by an experienced teacher external to the school. All students were required to attend as part of their regular home group curriculum. Participants completed an anonymous online survey on SurveyMonkey during class time 2 weeks before the program, immediately after the program, and at 6 weeks follow-up. The survey took students between 10 and 15 minutes to complete. Data was collected between March-October 2011.

\section{Measures}

Perceived help-seeking barriers were assessed with The Barriers to Engagement in Treatment Screen(BETS; (34)). The BETS is an 11-item measure identifying major barriers to seeking help from a health professional, with responses rated on a 4-point scale ( $0=$ "Agree" to $3=$ "Disagree"). All 11 BETS items were modified to focus on health professionals, rather than GPs, and two items were modified to include drug and alcohol problems ("if I tell a health professional about my drug or alcohol problems as well as emotional problems, I believe they will keep it a secret" and "I think health professionals are interested in drug and alcohol problems as well as emotional problems"). Chronbach's alphas for the modified scale ranged from $\pm=.82$ to $\pm=.92$ across the three time points. 
Intention to seek help was measured with the General Help Seeking Questionnaire (GSHQ; (35)), which required participants to indicate how likely they would be to seek help for an alcohol or drug problem from different sources, rated on a 5-point scale ( 1 = "very unlikely" to 5 = "very likely"). Help sources were divided into four main factors or categories; family (mother, father, friend, other relative), peer (friend, boyfriend/girlfriend), internet (chat room/blog, website), and formal sources (teacher, school counsellor, mental health professional, alcohol and drug worker, GP).

Confidence to seek help was measured with a single item: "How confident are you to seek help if you had an alcohol or drug problem?" Confidence to seek help for a peer was measured with a similar item, "How confident are you to assist a friend to seek help if they had an alcohol or drug problem?" Responses to both items were made on a 5-point Likert scale $(1=$ "Not confident at all" to $5=$ "Very confident").

Lifetime and recent alcohol use were assessed via the questions "during your life, on how many days have you had at least one drink of alcohol?" "during the past 30 days, on how many days did you have at least one drink of alcohol?" and "during the past 30 days, on how many days did you have 5 or more drinks of alcohol in a row, that is, within a couple of hours?'

\section{RESULTS}

\section{Baseline results}

In total, 247 students from the three secondary schools completed the pre-intervention assessment. Of these, 215 completed the post-intervention assessment, and 203 completed the 6-week follow-up, with a total of 196 students completing measures at all three time points (a retention rate of $66.0 \%$ ). There were no significant gender differences between participants who completed the measures at all three time points and participants who did not $\left(X^{2}=0.46\right.$, $p=0.55)$. Similarly, there were no significant differences between groups on baseline scores on the GHSQ $(\mathrm{t}(245)=-0.148, p=0.88)$, BETS $(\mathrm{t}(245)=0.129, p=0.90)$, confidence to seek help for a peer $(\mathrm{t}(245)=1.603, p=0.11)$, or lifetime alcohol use $\left(X^{2}=0.47, p=0.83\right)$. However, participants who completed measures at all three time points reported higher baseline confidence to seek help for themselves $(\mathrm{t}(245)=2.14, p=0.03)$. Demographic characteristics of the final sample of 196 participants are provided in Table 1. 


\section{Pre-intervention results}

Perceived barriers, intentions, and confidence at the pre-intervention assessment are displayed in Table 2. Regarding barriers, participants 'somewhat agreed' with positive statements about help-seeking from health professionals. Help-seeking intentions were highest in regard to family, followed by peers and formal sources (between 'unsure' and 'likely'), and the internet (between 'unsure' and 'unlikely'). Participants reported feeling between 'slightly confident' and 'confident' in regard to seeking help, for both self and peer. Females reported higher intentions to seek help from peers, and greater confidence to help a peer, compared to males. No other gender differences were found.

\section{Changes in barriers, confidence, and intentions}

Changes in perceived barriers, intentions, and confidence were analysed using repeatedmeasures ANOVAs, with gender included as a between-subjects factor. Intentions to seek help from individual help sources were examined if there was a significant main effect for overall help type (Table 3 ). There was a significant main effect of time on perceived barriers to seeking professional help, with Bonferroni-corrected post-hoc tests demonstrating a significant reduction in perceived barriers at the post-intervention and follow-up assessments. There was no significant interaction between barriers and gender.

There were significant main effects of time on intentions to seek help from formal sources, family, and the internet, but not from peers. In regard to formal sources, intentions increased significantly from pre- to post-intervention, before decreasing back to preintervention levels at follow-up. However, examination of individual help sources showed that increased intentions to seek help from school counsellors and alcohol and drug workers remained significantly higher at follow-up (only intentions to seek help from mental health professionals decreased at this time point). Conversely, intentions to seek help from family decreased significantly from pre- to post-intervention, with no significant change at followup. This pattern was consistent across individual help sources (mothers, fathers, and other relatives). Finally, despite the significant main effect of time on intentions to seek help from the internet, post-hoc tests did not demonstrate significant differences between time points.

Further analyses were conducted to explore the trend-level interactions between gender and intentions to seek help from formal and internet sources. Separate one-way 
ANOVAs demonstrated significant changes in help-seeking intentions from formal sources amongst females $(\mathrm{F}(2,198)=14.54, p<0.001)$, but only a trend-level change amongst males $(\mathrm{F}(2,190)=2.26, p=0.090)$. Bonferroni-corrected post-hoc tests revealed a significant increase in help-seeking intentions for females between the pre-intervention and postintervention assessment ( $\mathrm{p}<0.001)$, and a significant decrease (to pre-intervention levels) between the post-intervention and follow-up assessments $(\mathrm{p}=0.006)$. One-way ANOVAs examining help seeking from internet sources also revealed significant changes in intentions amongst females $(\mathrm{F}(2,198)=4.418, p=0.015)$, but not amongst males $(\mathrm{F}(2,198)=1.196$, $p=0.303)$. Amongst females, intention to seek help from internet sources did not change between the pre-intervention and post-intervention assessments $(p=0.562)$, but increased significantly between pre-intervention and follow-up $(p=0.022)$.

-Insert Table 3 here-

There was no change over time in confidence to seek help for self, however there was a significant main effect of time on confidence to seek help for peers. Confidence to seek help for peers increased between the pre-intervention and post-intervention assessments (to 'confident'), and decreased to pre-intervention levels at follow-up.

\section{DISCUSSION}

Substance use disorders are amongst the most common mental health problems experienced during adolescence. However, despite considerable investment in early intervention in recent years, including the development of school-based alcohol and drug education programs, less than $10 \%$ of young people with substance use disorders report accessing professional help (3). The MAKINGtheLINK: Seeking Help for Risky Drinking program is a school-based intervention that focuses on reducing perceived barriers to help-seeking for substance use problems during adolescence. The current study examined the effect of MAKINGtheLINK on help-seeking in a sample of 12-15 year old students. Findings indicate that the program decreased perceived barriers to seeking professional help, increased intentions to seek help from formal sources, decreased intentions to seek help from family, and increased confidence to seek help for a peer. The significant decrease in perceived barriers was maintained at the 6week follow-up. The decrease in intentions to seek help from family members was also 
maintained at follow-up, as was the increase in intentions to seek help from school counsellors and alcohol and drug workers, though not from formal sources overall.

Encouraging adolescents to seek help from appropriate sources is likely to reduce the long-term impact of early mental health problems (36). As such, the MAKINGtheLINK program focusses on teaching adolescents how to overcome perceived barriers to accessing and engaging with professional help, which may explain participants' decreased intentions to seek help from family at follow-up (i.e., the intervention may have shifted their help-seeking preferences away from informal and towards formal sources of help). In particular, the program appeared to increase adolescents' intentions to seek help from school counsellors and alcohol and drug workers, and decrease intentions to seek help from parents and other relatives. While encouraging adolescents to approach more appropriate help sources is an important goal, particularly as untrained adults demonstrate poor mental health literacy (37), there is evidence that parents (in particular, mothers) can play an important role in facilitating formal help-seeking during adolescence (25). As such, it is important to ensure that parents as well as other family members remain involved in the help-seeking process.

As predicted, the effects of the intervention did not differ significantly between males and females. However, there was some evidence to suggest that the intervention had a greater impact on help-seeking intentions amongst females, specifically in regard to formal and internet sources. While these results should be interpreted with caution given that the overall interactions between gender and help-seeking intentions did not reach significance, they highlight the need for further research examining the possibility that help-seeking interventions for substance use may differentially benefit males and females. This is of particular importance given that males are both more likely to experience substance use disorders and less likely to seek treatment for these (3). In particular, increasing intentions to seek formal help is likely to benefit males, as there is evidence that other people (particularly health professionals) have a strong influence on their decision to seek mental health treatment [4].

The baseline findings point towards differences in help-seeking for substance use compared to other mental health problems. Specifically, there were few pre-intervention differences in help-seeking between males and females, and intentions to seek help from family members were greater than intentions to seek help from peers. This latter finding could be influenced by the young age of participants, as decreased reliance on family as a help source becomes more apparent during mid-adolescence [13]. Alternatively, help-seeking preferences may vary depending on problem severity. Windle and colleagues [10] found that 
while most adolescents seek help from multiple informal sources, those with more severe substance use problems were less likely to seek help from their parents, and more likely to rely on peers as their sole form of support. This is consistent with research indicating that adolescents with substance use problems do not typically perceive parents to be a supportive resource (38).

-MAKINGtheLINK was designed to be both a prevention and early intervention program, and targeted students in the early secondary school years so that students have the skills to seek help for substance use problems before they reach a level of clinical significance. To our knowledge, the program is the first intervention to focus on overcoming perceived barriers to help-seeking for alcohol and other drug problems by helping adolescents develop the skills necessary to support their peers. In addition to improving gate-keeping skills, this is likely to have a positive impact on adolescents' ability to identify and seek help for their own substance use problems (39). Moreover, while the current intervention focussed on substance use, adolescents rely on each other for other mental health problems that could also be addressed by utilising peers as potential gate-keepers. These problems share common barriers, suggesting the mental health literacy and help-seeking skills that MAKINGtheLINK aims to develop are likely to be transferrable (36).

While the results of the current study are promising, there are a number of limitations to note. First, while the program decreased perceived barriers and increased intentions and confidence, no formal measures of behaviour were included. Although the measure used to assess intentions (the GHSQ) has been found to predict help-seeking behaviours (35), continued research is needed to determine whether the intervention actually increases engagement with help sources following the experience of substance use problems. Second, many of the changes that were found immediately post-intervention were not maintained at the 6-week follow-up. While it is encouraging that the reduction in perceived barriers remained significant at this time point, it is unclear whether this reflects a permanent or temporary change. Indeed, given the very short-term nature of the follow-up, there is a need for further research investigating whether the intervention leads to longer-term changes in help-seeking attitudes. Third, as only three high schools were involved in the intervention, the results may not be generalisable to other school settings. Finally, as this was an uncontrolled trial, it cannot be conclusively established that the changes observed at follow-up reflect the impact of the intervention. A cluster randomised controlled trial of MAKINGtheLINK is currently underway (40), which will hopefully address many of the limitations identified here, and will provide evidence regarding the potential long-term benefits of the program. 
In conclusion, the results of the current study suggest that MAKINGtheLINK has promise as a means of reducing the harms associated with adolescent substance use by reducing barriers to help-seeking, increasing help-seeking intentions, and increasing confidence amongst young people to help their peers. Further research is necessary to determine the effectiveness of the program before it can be recommended for inclusion within school curricula.

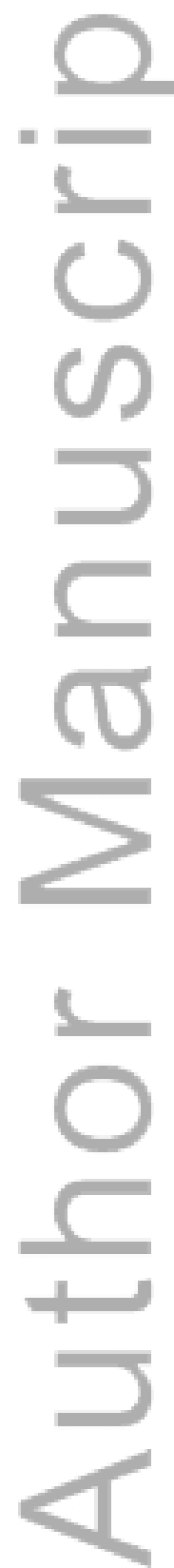




\section{References}

1. Lubman DI, Hides L, Yucel M, Toumbourou JW. Intervening early to reduce developmentally harmful substance use among youth populations. Medical Journal of Australia. 2007;187(7):S22-5.

2. McGorry PD, Purcell R, Goldstone S, Amminger GP. Age of onset and timing of treatment for mental and substance use disorders: implications for preventive intervention strategies and models of care. Current Opinion in Psychiatry. 2011;24(4):301-6.

3. = Reavley NJ, Cvetkovski S, Jorm AF, Lubman DI. Help-seeking for substance use, anxiety and affective disorders among young people: Results from the 2007 Australian National Survey of Mental Health and Wellbeing. Australian and New Zealand Journal of Psychiatry. 2010;44(8):729-35.

4. Rickwood DJ, Deane FP, Wilson CJ. When and how do young people seek professional help for mental health problems? Medical Journal of Australia. 2007;187(7):S35. 5. Currie JC. Best Practices: Treatment and Rehabilitation for Youth with Substance Use Problems: Health Canada Ottawa; 2001.

6. Myers MG. Smoking intervention with adolescent substance abusers: Initial recommendations. Journal of Substance Abuse Treatment. 1999;16(4):289-98.

7. Slesnick N, Meyers RJ, Meade M, Segelken DH. Bleak and hopeless no more: Engagement of reluctant substance-abusing runaway youth and their families. Journal of Substance Abuse Treatment. 2000;19(3):215-22.

8. Ballon B, Kirst M, Smith P. Youth help-seeking expectancies and their relation to help-seeking behaviours for substance use problems. Addiction Research \& Theory. 2004;12(3):241-60.

9. Metrik J, Frissell KC, McCarthy DM, D'Amico EJ, Brown SA. Strategies for reduction and cessation of alcohol use: Adolescent preferences. Alcoholism: Clinical and Experimental Research. 2003;27(1):74-80.

10. Windle M, Miller-Tutzauer C, Barnes GM, Welte J. Adolescent Perceptions of HelpSeeking Resources for Substance Abuse. Child Development. 1991;62(1):179-89.

11. Benson PL. Help-seeking for alcohol and drug problems: To whom do adolescents turn? Journal of Child \& Adolescent Substance Abuse. 1990;1(1):83-94.

12. Weiss S, Moore M. Why, where and with whom do Israeli teenagers drink? To whom do they turn for help with alcohol problems? Alcohol and Alcoholism. 1994;29(4):465-71. 
13. Rickwood D, Deane FP, Wilson CJ, Ciarrochi J. Young people's help-seeking for mental health problems. Australian e-Journal for the Advancement of Mental Health. 2005;4(3) Supplement.

14. Cartmill T, Deane F, Wilson C. Gatekeeper training for youth workers: Impact on their help-seeking and referral skills. Youth Studies Australia. 2009;28(1):5.

15. Jorm AF, Wright A, Morgan AJ. Beliefs about appropriate first aid for young people with mental disorders: Findings from an Australian national survey of youth and parents. Early Intervention in Psychiatry. 2007;1(1):61-70.

16. White VM, Bariola E. Australian Secondary School Students' Use of Tobacco, Alcohol, and Over-the-counter and Illicit Substances in 2011: Report: National Drug Strategy, Department of Health and Ageing; 2012.

17. AIHW. 2007 National Drug Strategy Household Survey: detailed findings. Canberra: AIHW, 2008.

18. Bonomo YA. Adolescent alcohol problems: whose responsibility is it anyway? Medical Journal of Australia. 2005;183(8):430.

19. Roche A, Bywood P, Borlagdan J, Lunnay B, Freeman T, Lawton L, et al. Young people and alcohol: The role of cultural influences. Adelaide: National Centre for Education and Training on Addiction. 2007.

20. Rickwood D, Thomas K. Conceptual measurement framework for help-seeking for mental health problems. Psychology research and behavior management. 2012;5:173.

21. Komiya N, Good GE, Sherrod NB. Emotional openness as a predictor of college students' attitudes toward seeking psychological help. Journal of Counseling Psychology. 2000;47(1):138.

22. Schonert-Reichl KA, Muller JR. Correlates of help-seeking in adolescence. Journal of Youth and Adolescence. 1996;25(6):705-31.

23. Eisenberg D, Downs MF, Golberstein E, Zivin K. Stigma and help seeking for mental health among college students. Medical Care Research and Review. 2009;66(5):522-41.

24. Sen B. Adolescent propensity for depressed mood and help seeking: race and gender differences. Journal of Mental Health Policy and Economics. 2004;7(3):133-45.

25. Houle J, Chagnon F, Lafortune D, Labelle R, Paquette KB. Correlates of help-seeking behaviour in adolescents experiencing a recent negative life event. Canadian Journal of Family and Youth/Le Journal Canadien de Famille et de la Jeunesse. 2013;5(1):39-63.

26. Burns JR, Rapee RM. Adolescent mental health literacy: Young people's knowledge of depression and help seeking. Journal of Adolescence. 2006;29(2):225-39. 
27. Nicholas J, Oliver K, Lee K, O’Brien M. Help-seeking behaviour and the Internet: An investigation among Australian adolescents. Australian e-journal for the Advancement of Mental Health. 2004;3(1):16-23.

28. Burns JM, Davenport TA, Durkin LA, Luscombe GM, Hickie IB. The internet as a setting for mental health service utilisation by young people. Medical Journal of Australia. 2010;192(11):S22.

29. D'Amico EJ, McCarthy DM, Metrik J, Brown SA. Alcohol-related services: Prevention, secondary intervention, and treatment preferences of adolescents. Journal of Child \& Adolescent Substance Abuse. 2004;14(2):61-80.

30. D'Amico EJ. Factors that impact adolescents' intentions to utilize alcohol-related prevention services. The Journal of Behavioral Health Services \& Research. 2005;32(3):33240 .

31. Berridge BJ, Hall K, Dillon P, Hides L, Lubman DI. MAKINGtheLINK: a schoolbased health promotion programme to increase help-seeking for cannabis and mental health issues among adolescents. Early Intervention in Psychiatry. 2011;5(1):81-8.

32. Fisher JD, Fisher WA, Shuper PA. The information-motivation-behavioral skills model of HIV preventive behavior. Emerging Theories in Health Promotion Practice and Research. 2009;2:21-64.

33. McEachan RRC, Conner M, Taylor NJ, Lawton RJ. Prospective prediction of healthrelated behaviours with the theory of planned behaviour: A meta-analysis. Health Psychology Review. 2011;5(2):97-144.

34. Deane FP, Wilson CJ, Russell N. Brief report: Impact of classroom presentations about health and help-seeking on rural Australian adolescents' intentions to consult health care professionals. Journal of Adolescence. 2007;30(4):695-9.

35. Wilson CJ, Deane FP, Ciarrochi J, Rickwood D. Measuring help-seeking intentions: Properties of the general help-seeking questionnaire. Canadian Journal of Counselling. 2005;39(1):15.

36. Wilson CJ, Bushnell JA, Caputi P. Early access and help seeking: practice implications and new initiatives. Early Intervention in Psychiatry. 2011;5(s1):34-9.

37. Jorm AF, Korten AE, Jacomb PA, Christensen H, Rodgers B, Pollitt P. "Mental health literacy": a survey of the public's ability to recognise mental disorders and their beliefs about the effectiveness of treatment. MJA. 1997:166-82.

38. Holden MG, Brown SA, Mott MA. Social support network of adolescents: Relation to family alcohol abuse. The American Journal of Drug and Alcohol Abuse. 1988;14(4):487-98. 
39. Kitchener BA, Jorm AF. Mental health first aid training in a workplace setting: a randomized controlled trial [ISRCTN13249129]. BMC psychiatry. 2004;4(1):1.

40. Lubman D, Berridge BJ, Blee F, Jorm AF, Allen NB, McKay-Brown L, et al. A school-based health promotion program to increase help-seeking for substance use and mental health problems: study protocol for a randomised controlled trial. Trials. 2016;17:393.

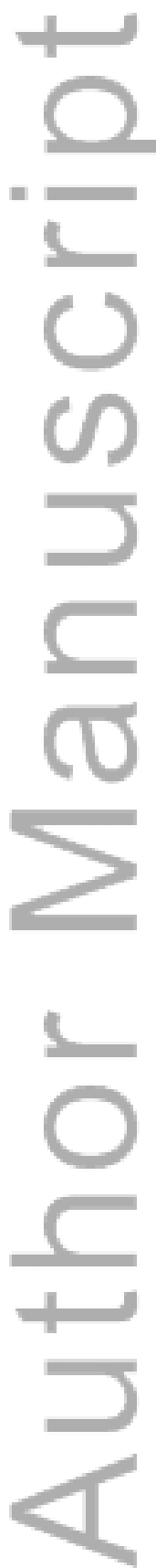


Table 1. Participant demographics

\begin{tabular}{ll}
\hline Demographics & Final sample $(\mathrm{n}=196)$ \\
\hline Age at baseline (M, SD) & $13.3(0.54)$ \\
Age range at baseline & $12-15$ years \\
Gender & \\
Male (\%) & $96(49.0 \%)$ \\
Female (\%) & $100(51.0 \%)$ \\
Country of birth & \\
Australia (\%) & $175(86.3 \%)$ \\
New Zealand (\%) & $1(2 \%)$ \\
Other (\%) & $20(11.8 \%)$ \\
Home language & \\
English (\%) & $159(81.1 \%)$ \\
Other (\%) & $37(18.9 \%)$ \\
Alcohol use & \\
Lifetime used (\%) & \\
Lifetime days drinking (M, SD) & $66(33.7 \%)$ \\
Lifetime days drinking (range) & $0.68(1.27)$ \\
Recent ${ }^{\mathrm{a}}(\%)$ & $0-100+$ \\
Recent harmful ${ }^{\mathrm{b}}(\%)$ & $21(10.7 \%)$ \\
\hline
\end{tabular}

${ }^{\mathrm{a}}$ Use over the past 30 days

${ }^{\mathrm{b}}$ Consumed $5+$ standard drinks over the past 30 days

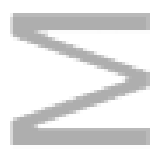

Table 2. Help-seeking barriers, intentions, and confidence (pre-intervention)

\begin{tabular}{|c|c|c|c|c|c|}
\hline & Full sample & Male & Female & Difference & \\
\hline & $\mathrm{M}(\mathrm{SD})$ & $\mathrm{M}(\mathrm{SD})$ & $\mathrm{M}(\mathrm{SD})$ & $\mathrm{t}(1,245)$ & $p$ \\
\hline Barriers & $1.08(0.51)$ & $1.06(0.52)$ & $1.11(0.51)$ & -0.74 & 0.456 \\
\hline \multicolumn{6}{|c|}{ Intentions } \\
\hline Formal & $=3.08(0.88)$ & $3.07(0.92)$ & $3.09(0.84)$ & -0.28 & 0.782 \\
\hline Family & $3.87(0.93)$ & $3.80(0.98)$ & $3.93(0.89)$ & -1.10 & 0.273 \\
\hline Peer & $3.40(0.85)$ & $3.21(0.87)$ & $3.57(0.79)$ & -3.41 & 0.001 \\
\hline Internet & $2.33(1.06)$ & $2.27(1.11)$ & $2.39(1.01)$ & -0.95 & 0.342 \\
\hline \multicolumn{6}{|c|}{ Confidence } \\
\hline & $2.67(1.22)$ & $2.65(1.34)$ & $2.53(1.18)$ & 0.78 & 0.434 \\
\hline Peer & $2.64(1.27)$ & $2.29(1.45)$ & $2.84(1.11)$ & -3.36 & 0.001 \\
\hline
\end{tabular}


Table 3. Change in barriers, help-seeking intentions, and confidence

\begin{tabular}{|c|c|c|c|c|c|c|c|}
\hline & Pre & Post & Follow-up & \multicolumn{2}{|c|}{ Main effect } & \multicolumn{2}{|c|}{ Gender interaction } \\
\hline & M & M & M & $\mathrm{F}(2,388)$ & $p$ & $\mathrm{~F}(2,388)$ & $p$ \\
\hline Barriers & $1.08(0.51)^{\mathrm{a}}$ & $0.92(0.61)^{b}$ & $0.98(0.54)^{b}$ & 10.42 & $<0.001$ & 0.98 & 0.370 \\
\hline \multicolumn{8}{|l|}{ Intentions } \\
\hline Formal & $3.23(0.92)^{\mathrm{a}}$ & $3.51(0.91)^{b}$ & $3.34(0.93)^{\mathrm{a}}$ & 11.94 & $<0.001$ & 2.51 & 0.083 \\
\hline School counsellor & $2.91(1.21)^{\mathrm{a}}$ & $3.55(1.21)^{b}$ & $3.13(1.20)^{\mathrm{b}}$ & 28.25 & $<0.001$ & 3.84 & 0.023 \\
\hline Mental health professional & $3.53(1.25)^{\mathrm{a}}$ & $3.80(1.14)^{b}$ & $3.62(1.17)^{\mathrm{a}}$ & 4.77 & 0.009 & 0.40 & 0.665 \\
\hline Alcohol and drug worker & $3.28(1.21)^{\mathrm{a}}$ & $3.66(1.20)^{\mathrm{b}}$ & $3.52(1.20)^{\mathrm{b}}$ & 10.02 & $<0.001$ & 0.58 & 0.559 \\
\hline Doctor & $3.38(1.12)$ & $3.45(1.18)$ & $3.44(1.06)$ & 0.42 & 0.650 & 0.56 & 0.563 \\
\hline Teacher & $2.32(1.07)$ & $2.33(1.06)$ & $2.23(1.07)$ & 0.90 & 0.405 & 1.18 & 0.307 \\
\hline Phone help line & $2.99(1.22)$ & $3.09(1.31)$ & $2.96(1.26)$ & 1.08 & 0.339 & 2.13 & 0.122 \\
\hline Family & $3.90(0.92)^{\mathrm{a}}$ & $3.45(1.01)^{\mathrm{b}}$ & $3.52(1.03)^{\mathrm{b}}$ & 29.28 & $<0.001$ & 1.57 & 0.210 \\
\hline Mother & $4.24(1.10)^{\mathrm{a}}$ & $3.69(1.25)^{\mathrm{b}}$ & $3.85(1.22)^{b}$ & 31.80 & $<0.001$ & 0.21 & 0.808 \\
\hline Father & $3.91(1.30)^{\mathrm{a}}$ & $3.43(1.29)^{\mathrm{b}}$ & $3.54(1.28)^{b}$ & 4.77 & 0.009 & 0.57 & 0.561 \\
\hline Other relative & $3.54(1.06)^{\mathrm{a}}$ & $3.23(1.21)^{\mathrm{b}}$ & $3.19(1.18)^{b}$ & 10.02 & 0.001 & 1.34 & 0.258 \\
\hline Peer & $3.38(0.84)$ & $3.33(0.94)$ & $3.27(1.08)$ & 1.01 & 0.361 & 0.27 & 0.757 \\
\hline Internet & $2.32(1.08)^{\mathrm{a}}$ & $2.33(1.15)^{\mathrm{a}}$ & $2.50(1.17)^{\mathrm{a}}$ & 3.42 & 0.035 & 2.46 & 0.086 \\
\hline \multicolumn{8}{|l|}{ Confidence } \\
\hline Self & $2.67(1.22)^{\mathrm{a}}$ & $2.60(1.43)^{\mathrm{a}}$ & $2.69(1.31)^{\mathrm{a}}$ & 0.41 & 0.660 & 1.17 & 0.839 \\
\hline Peer & $2.64(1.27)^{\mathrm{a}}$ & $2.93(1.13)^{b}$ & $2.63(1.37)^{\mathrm{a}}$ & 5.50 & 0.005 & 2.03 & 0.133 \\
\hline
\end{tabular}

Means with different superscripts are significantly different $(\mathrm{p}<0.05$, Bonferroni-corrected)

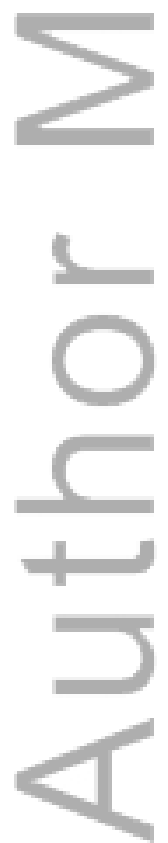




\section{University Library}

\section{- M M N E R VA A gateway to Melbourne's research publications}

Minerva Access is the Institutional Repository of The University of Melbourne

Author/s:

Lubman, DI;Cheetham, A;Berridge, BJ;McKay-Brown, L

Title:

MAKINGtheLINK: A school-based intervention to improve help-seeking for substance use problems

Date:

2018-10-01

Citation:

Lubman, D. I., Cheetham, A., Berridge, B. J. \& McKay-Brown, L. (2018). MAKINGtheLINK: A school-based intervention to improve help-seeking for substance use problems. EARLY INTERVENTION IN PSYCHIATRY, 12 (5), pp.915-921. https://doi.org/10.1111/eip.12402.

Persistent Link:

http://hdl.handle.net/11343/292917 